\title{
O SINAES NOS INSTITUTOS FEDERAIS: ADEQUAÇÃO E PERTINÊNCIA NO ÂMBITO DA AVALIAÇÃO INSTITUCIONAL
}

\author{
M. A. C. MORAES, J. C. R. SOARES, F. Y. OKUYAMA*, J. G. NUNES E G. S. PIO \\ Instituto Federal do Rio Grande do Sul - Campus Porto Alegre \\ fabio.okuyama@poa.ifrs.edu.br*
}

Artigo submetido em outubro/2013 e aceito em dezembro/2013

DOI: $10.15628 /$ rbept.2013.3563

\section{RESUMO}

Os Institutos Federais de Educação, Ciência e Tecnologia (IFs) surgem como uma nova proposta educacional, com o compromisso de unir a construção de conhecimentos à transformação da sociedade. Esse caráter inovador dos IFs decorre das especificidades de sua identidade institucional, caracterizado pela oferta curricular verticalizada da educação, a partir da educação básica, passando pelo ensino técnico, formação inicial e continuada até os níveis superiores. Esta complexidade de organização dos IFs cria a necessidade de diferenciarem-se das universidades, pois estas especificidades produzem sua identidade singular. Atualmente o SINAES (Sistema Nacional de Avaliação da Educação Superior) é a política que avalia e regulamenta as instituições que ofertam educação superior. Esse estudo busca identificar os desencontros entre o SINAES e os IFs no âmbito da avaliação. A análise parcial da pesquisa mostra a existência de lacunas em cinco das dez dimensões avaliativas propostas pelo SINAES, apontando a urgência da reflexão no conceito de verticalização, para que os instrumentos de avaliação atendam às singularidades dos IFs.

PALAVRAS-CHAVE: Institutos Federais, SINAES, Avaliação institucional, Regulação, Gestão da educação pública.

\section{SINAES AND FEDERAL INSTITUTES: THE ADEQUATENESS AND PERTINENCE IN THE INSTITUTIONAL EVALUATION}

\begin{abstract}
The Federal Institutes of Education, Science and Technology (IFs) appear as a new educational proposal, committed to join the construction of knowledge to the transformation of society. This innovative character of IFs derives from the specifics of their institutional identity, characterized by vertical curricular provision of education, from basic education, through technical education, initial and continuing education to higher levels. This particularity of organization of IFs creates the necessity to differentiate themselves from universities
\end{abstract}

because these specificities produce its unique identity. Currently SINAES (National Higher Education Evaluation System) is the policy that assesses and regulates the institutions that offer higher education. This study seeks to identify the mismatches between the SINAES and IFs under evaluation. The partial analysis shows that there are discrepancies in five of the ten dimensions evaluation proposals by SINAES, pointing out the urgency of reflecting about the concept of vertical integration, so that the assessment tools meet the singularities of IFs.

KEYWORDS: Federal Institutes, SINAES, Institutional Evaluation, Regulation, Educational management policy 


\section{APRESENTAÇÃO}

Os Institutos Federais de Educação, Ciência e Tecnologia (IFs) criados pela lei 11.892/08 de dezembro de 2008, surgem no cenário educacional, com o compromisso de promover um ensino integral voltado à construção de conhecimentos e à quebra da hierarquização dos saberes, rompendo com uma lógica mercadológica da formação de mão de obra qualificada para suprir as necessidades do capital (BRASIL, 2008).

Para isso, essas instituições de ensino buscam a transformação da sociedade por meio de uma educação crítica, reflexiva e emancipatória, promovendo a educação integral dos sujeitos que até então não tinham a oportunidade de estudar.

Esse caráter inovador conferido aos Institutos Federais se dá pelo conjunto especificidades contribuintes para a formação de sua identidade institucional singular, pois além de possuírem um desenho curricular pedagógico verticalizado, se caracterizam pela oferta da educação básica, por meio do nível médio integrado ao técnico, até a educação superior, envolvendo, inclusive, a oferta de cursos de pós-graduação (lato e stricto sensu).

Devido à complexidade que marca sua identidade institucional, os Institutos Federais enfrentam a necessidade de diferenciarem-se das universidades, enquanto instituições de ensino. No entanto, a oferta da educação básica não garante tal diferenciação, pelo fato de possuírem a prerrogativa de, tal qual a universidade, oferecerem cursos de graduação e pós-graduação.

O SINAES (Sistema Nacional de Avaliação da Educação Superior) é a política governamental responsável pela avaliação e regulação das instituições que ofertam ensino superior. Neste processo de construção e avaliação institucional é fundamental que sejam elaborados e aplicados instrumentos que atendam às especificidades dos IFs, pois são estas especificidades que conferem sua identidade.

A regulação dos Institutos Federais incide sobre o processo de construção de sua identidade, portanto, precisa acontecer à luz do que a política educacional dessas instituições propaga. Conforme LEITE (2005) o processo de avaliação com informações organizadas favorece o entendimento de situações e relações, construção de sentidos e conhecimentos sobre sujeitos, estruturas e atividades que ocorrem em uma instituição educativa num determinado período de tempo. Em verdade, uma avaliação indica qual o conhecimento que vale - o que se deve saber a respeito do quê, o que se valoriza em detrimento do quê. Nesse sentido, entende-se que "a avaliação condensa o significado da totalidade do dispositivo pedagógico" (BERNSTEIN, 1998, p.66), e este especializa formas de consciência, controla significados (o que se pode e não se pode pensar).

Nesse sentido, esse estudo busca por meio de análise documental, identificar os encontros e desencontros entre o SINAES e os Institutos Federais no âmbito da avaliação institucional, por meio da análise dos documentos oficiais que tratam das concepções e diretrizes dos IFs, e do SINAES, no que diz respeito à possibilidade de flexibilização do documento.

Nossa abordagem se inicia percorrendo um pouco da história da educação profissional e tecnológica, refletindo sobre as características identitárias dos Institutos Federais e chegando até uma análise das dimensões avaliativas, nas quais nos debruçamos sobre cinco das dez dimensões 
propostas pelo SINAES e possíveis indicadores que poderiam ser agregados a fim de considerar as políticas da nova instituição no processo de regulação e avaliação.

\section{UM NOVO OLHAR PARA A EDUCAÇÃo PROFISSIONAL E TECNOLÓGICA NACIONAL}

A formação para o trabalho por meio da utilização da educação inicia seu contexto histórico no Brasil, em 1909, com a criação de dezenove Escolas de Aprendizes Artífices pelo então presidente Nilo Peçanha. Essas escolas tinham como principal objetivo, o controle social dos cidadãos da classe proletária, considerados tendenciosos à aquisição de hábitos prejudiciais à sociedade como um todo, ou seja, constituía uma forma de moralizar as pessoas, reprimindo vícios comuns. Além disso, a educação surgia com o intuito de qualificá-los para servirem de mão de obra barata, atendendo, assim, às necessidades econômicas do Estado brasileiro da época.

Sem desconsiderar tais concepções que influenciam a visão de trabalho ao longo do tempo, também é importante que sejam realizadas reflexões sobre a dimensão do trabalho de acordo com sua natureza ontológica, ou seja, é fundamental pensar que o trabalho está vinculado diretamente com a própria forma de agir dos seres humanos. Nesse sentido, é preciso, acima de tudo, perceber que os seres humanos fazem parte da natureza, e são capazes de interagir constantemente com ela, e é a partir da transformação desse meio em que vivem que são retirados recursos para manter a condição básica da vida, sendo um processo produzido pelos homens (FRIGOTTO; CIAVATTA; RAMOS, 2005).

Ao relacionar o trabalho com seu sentido ontológico, é impossível não compará-lo com a finalidade do trabalho no âmbito da sociedade atual, onde o sentido do trabalho se reduz à visão de emprego, à necessidade frequente de enfrentamento de condições subumanas e lutas constantes pelo mínimo de dignidade e de preservação do direito dos cidadãos.

Seguindo a lógica de mercado, torna-se mais cômodo promover uma educação voltada especificamente às demandas econômicas, restringindo os estudantes de uma formação crítica e social.

Nessa perspectiva, a partir do início do século XXI, as diretrizes políticas de governo passaram a assumir a educação como política social emancipatória, ou seja, como um direito da população e como fator de transformação social, destacando a importância de uma visão diretamente voltada ao desenvolvimento do padrão de vida dos cidadãos até então excluídos desse direito e, também, da região em que vivem.

A formação dos trabalhadores ganhou relevo, bem como a perspectiva do trabalho com princípio educativo, que envolve a construção de uma escola única, de cultura geral humanística, formativa e que equilibre o desenvolvimento da capacidade de trabalhar manualmente com o desenvolvimento das capacidades do trabalho intelectual, ou seja, formando o cidadão na sua integralidade, de modo que possa interagir com o mundo em que vive de forma crítica e consciente (FRIGOTTO; CIAVATTA; RAMOS, 2005).

É justamente partindo dessa visão, que se iniciou a expansão da rede federal de ensino, na qual se ampliou a oferta de Escolas Federais em estados que ainda não as possuíam, priorizando as periferias, metrópoles e cidades interioranas, proporcionando assim que os cidadãos moradores dessas regiões tivessem acesso à educação profissional e tecnológica, com vistas à diminuição da 
desigualdade social. Após a primeira expansão, a segunda etapa caracterizou-se pelo aumento da oferta de vagas dessas instituições, bem como pela ampliação das unidades de ensino, tendo como meta 500 mil matrículas até 2010.

A partir desse crescimento expressivo na rede federal de ensino, surge a necessidade de uma nova institucionalidade, ou seja, de legitimar a existência dessa instituição e de sua nova proposta político-pedagógica - capazes de construir novos sujeitos históricos que possam compreender e transformar o mundo em que vivem superando as ideias neoliberais (PACHECO, 2011), deixando de ser um "sujeito - mercado" alimentado pelo capital (FRIGOTTO; CIAVATTA; RAMOS, 2005).

Assim surgem os Institutos Federais de Educação, Ciência e Tecnologia (IFs), com o objetivo de fortalecer a educação brasileira, baseados em uma educação humanístico-técnico-científica, comprometidos com a realidade local e com a construção dos saberes dos cidadãos brasileiros, levando em consideração as demandas sociais em prol de uma sociedade mais justa e igualitária.

\section{AS ESPECIFICIDADES FORMADORAS DA NOVA IDENTIDADE INSTITUCIONAL}

A pesquisa que deu origem a esse artigo teve como um de seus caminhos metodológicos a análise do documento oficial de concepções e diretrizes dos Institutos Federais, buscando identificar os elementos que contribuem para a formação da identidade institucional dos Institutos Federais e, a partir disso, refletir sobre a relevância do SINAES (Sistema Nacional de Avaliação da Educação Superior) no âmbito da avaliação e regulamentação dessas novas instituições de ensino.

Os Institutos Federais (IFs) representam um modelo de instituição que, em razão da sua organização vertical, visam "à superação de dicotomias entre ciência e tecnologia, entre teoria e prática, visam ultrapassar a visão compartimentalizada de saberes; buscam a apropriação com maior profundidade do conhecimento" (BRASIL, 2008, p. 31).

Seu desenho curricular contempla a oferta de educação básica, principalmente em cursos de ensino médio integrado à educação profissional técnica de nível médio integrado (incluindo a oferta de cursos PROEJA); ensino técnico concomitante e subsequente; cursos superiores de tecnologia, licenciatura e bacharelado em áreas em que a ciência e a tecnologia são componentes determinantes, em particular as engenharias, bem como, programas de pós-graduação lato e stricto sensu, sem deixar de assegurar a formação inicial e continuada do trabalhador e dos futuros trabalhadores (Brasil, 2008, p. 27).

A verticalização do ensino surge como um princípio que viabiliza o processo de democratização do ensino e a organização curricular dos Institutos Federais, conferindo um caráter singular a este último. Essa especificidade, que difere os Institutos Federais das Universidades, tem como característica proporcionar aos educadores uma transição entre os diferentes níveis e modalidades de ensino. Os docentes que atuam nesse modelo verticalizado têm a possibilidade de construir vínculos e de estabelecer metodologias adequadas aos diferentes níveis de ensino, de forma reflexiva e contextualizada, a fim de integrar os eixos de pesquisa, ensino e extensão.

Aos discentes, a verticalização justifica-se no compartilhamento de projetos, espaços pedagógicos e laboratórios de maneira privilegiada, possibilitando a troca de saberes e experiências entre os diferentes níveis educacionais, reduzindo o distanciamento entre as 
formações. Além disso, proporcionam aos mesmos a possibilidade de cursar os diferentes níveis e modalidade de ensino na mesma instituição.

Segundo PACHECO (2011), a verticalização vai além da oferta simultânea de cursos em diferentes níveis, pois permite um diálogo construtivo entre as formações, conferindo ao currículo dos Institutos características organizacionais específicas e dialógicas, de forma que os docentes possuem liberdade para desenvolver suas atividades de ensino.

A transversalidade associada à verticalização do ensino destaca-se como aspecto contribuinte para a singularidade do desenho curricular dessas instituições educacionais, visto que auxilia na escolha e organização curricular e na ação pedagógica, no que diz respeito à tomada das dimensões do trabalho, da cultura, da ciência e da tecnologia (PACHECO, 2011).

Esse conjunto de elementos, que confere singularidade aos Institutos Federais, contribui para o combate das desigualdades e para a quebra da hierarquização dos saberes, educando os cidadãos não apenas para o mercado de trabalho, mas sim para o exercício de sua cidadania no mundo do trabalho, promovendo a construção de uma nova identidade social através da transformação da sociedade brasileira.

Nessa perspectiva, para que ocorra a transformação social em escala global, os Institutos Federais têm como um de seus objetivos, colaborar para o desenvolvimento local e regional, buscando alternativas para a redução da exclusão do ensino, a fim de estabelecer mudanças na qualidade de vida dos cidadãos, proporcionando a estes, espaços educativos voltados à construção de saberes e à democratização do conhecimento.

Entende-se que ao pensar no desenvolvimento local e regional, por meio da oferta de cursos direcionados às necessidades do lócus, os cidadãos tendem a se apropriar dos conhecimentos visando à melhoria de sua própria realidade. Nesse sentido, os Institutos Federais reafirmam-se como importante instrumento de resgate da cidadania e de construção de uma sociedade igualitária, por meio da educação profissional e tecnológica voltada para o domínio intelectual, e não apenas para a geração de mão de obra especializada.

Segundo PACHECO (2011), esse novo desenho institucional traz como principal função a intervenção na realidade local e regional, objetivando a transformação da sociedade no âmbito de uma esfera maior, o que reafirma a importância de sua natureza pública como agente combatente das desigualdades.

Para que essa transformação social ocorra de fato é necessário propiciar aos diferentes grupos sociais a possibilidade de participação nas decisões do país de maneira coletiva. Nesse sentido entende-se que a inclusão educacional funciona como uma ferramenta de construção dos saberes, proporcionando aos indivíduos condições para o domínio dos conhecimentos. No entanto, no Brasil contemporâneo a oferta de profissionais qualificados nas áreas tecnológicas é menor do que a demanda, o que demonstra uma carência educacional nos diferentes setores produtivos.

Dessa forma, se evidencia a necessidade da geração de mão de obra qualificada, com intuito de fortalecer a base produtiva do país, o que não significa dizer que essa formação se dá exclusivamente para favorecer a economia. Os Institutos Federais surgem com a ideia de pensar a educação não apenas como fator de desenvolvimento econômico, mas como forma de pensar o trabalho como princípio educativo, como aspecto contribuinte para a formação de uma postura 
cidadã integral, na qual o sujeito possa desenvolver criticidade e visão política a respeito da sociedade em que está inserido.

É possível refletir sobre as necessidades educacionais apontadas pela sociedade atual, compreendendo o papel desse novo modelo institucional comprometido com a construção intelectual dos sujeitos, para que estes atuem de forma consciente e autônoma na construção de uma nação igualitária, democrática e solidária.

É partindo da complexidade organizacional dos Institutos Federais enquanto instituições de ensino, que surge a necessidade de diferenciação das universidades, pois embora os Institutos ofereçam a educação básica, esse fato não garante tal diferenciação, devido à premissa "universitária" da oferta de graduação e pós-graduação.

$\mathrm{Na}$ perspectiva de construir indicadores específicos às características dos Institutos Federais, para que estes não se tornem "mini universidades", é que esse estudo alerta para o fato de que os processos de avaliação e de regulação institucional, definidos pelo SINAES, precisam se utilizar de instrumentos que atendam às especificidades dos Institutos Federais, pois são estas especificidades que conferem sua identidade, diferenciando-os das demais instituições de ensino.

\section{ANÁLISE DAS DIMENSÕES AVALIATIVAS DO SINAES: PROPOSTA DA ADEQUAÇÃO ÀS ESPECIFICIDADES DOS INSTITUTOS FEDERAIS}

O SINAES é uma política de Estado destinada a avaliar as instituições de ensino que ofertam a educação superior, e parte do pressuposto de que "a avaliação deve ser entendida como estrutura de poder que age sobre os indivíduos, as instituições e os sistemas" (BRASIL, 2009, p. 91), ou seja, deve articular um sistema de avaliação com autonomia própria dos processos educativos e emancipatórios, de natureza regulatória, buscando fortalecer o compromisso educativo das instituições.

Considerando a complexidade que existe diante da avaliação da educação superior, o SINAES necessita da utilização de diversos instrumentos e metodologias, constituindo um sistema avaliativo que compreenda dimensões da realidade institucional. Para isso, esse documento fundamenta-se em alguns princípios e critérios considerados fundamentais para justificar a operacionalização dos processos avaliativos.

O objetivo central da análise do documento oficial que estabelece o SINAES é verificar se existe a possibilidade de flexibilizar esse documento, de modo que este passe a atender às especificidades dos Institutos Federais descritas no terceiro item (subtítulo) desse trabalho.

O SINAES aponta em um dos pressupostos que se baseia como referencial teórico, que o processo avaliativo deve respeitar a identidade e a diversidade institucional em um sistema diversificado:

A avaliação da educação superior deve ter uma concepção tal que atenda ao critério da diversidade institucional; deve contribuir para a construção de uma política e de uma ética de educação superior em que sejam respeitados o pluralismo, a alteridade, as diferenças institucionais, mas também o espírito de solidariedade e cooperação. (BRASIL, 2009, p. 98). 
Na mesma perspectiva, o documento traz a ideia de que mesmo sendo necessário o cumprimento de normas, critérios e indicadores previstos legalmente, a fim de garantir a qualidade do ensino, também é importante que seja considerado o contexto histórico da instituição, não como modo de individualiza-la, mas sim, como forma de promover a solidariedade interinstitucional:

\begin{abstract}
Cada instituição tem sua história e constrói concretamente suas formas e conteúdos próprios que devem ser respeitados. No desenho da regulação e da avaliação, cada instituição deveria submeter-se ao cumprimento das normas oficiais e aos critérios, indicadores e procedimentos gerais, porém, ao mesmo tempo, exercitar sua liberdade para desenvolver, no que for possível e desejável, processos avaliativos que também correspondam a objetivos e necessidades específicos. (BRASIL, 2009, p. 98).
\end{abstract}

Esses fragmentos retirados do documento oficial do SINAES servem para exemplificar uma prerrogativa demonstrada a todo o momento acerca do processo de avaliação, que é a possibilidade de adequação nos diversos instrumentos constituintes da avaliação institucional, dentre eles o instrumento de avaliação externa, construído pela CONAES (Comissão Nacional de Avaliação da Educação Superior), juntamente com a DAES (Diretoria e Avaliação da Educação Superior), do Instituto Nacional de Estudos e Pesquisas Educacionais Anísio Teixeira (INEP).

Nas colocações iniciais a respeito das razões que norteiam a construção de tal instrumento, o então Ministro da Educação menciona em 2008 que:

A compreensão da avaliação como um processo dinâmico, que exige mediação pedagógica permanente, impõe ao Ministério da Educação a responsabilidade de rever periodicamente os seus instrumentos e procedimentos de avaliação, de modo a ajustá-los aos diferentes contextos e situação que se apresentam no cenário da educação superior e torná-los elementos balizadores da qualidade que se deseja para a educação superior brasileira. (BRASIL, 2009, p. 126).

No entanto, o que é possível perceber é que, embora os Institutos Federais tenham surgido no ano de 2008 como uma nova proposta de educação para o cenário nacional, e levando em consideração fragmentos retirados do documento oficial do SINAES, em sua última edição, não houve nenhuma mudança no instrumento de avaliação externa para que fossem contempladas as especificidades características dos Institutos Federais. O que não significa dizer, que essas novas instituições estejam obstantes ao processo de avaliação e regulamentação, pelo contrário, o que se pretende é demonstrar que se faz necessário considerar a existência dos Institutos Federais nos instrumentos, que em sua generalidade referem-se aos padrões exigidos para as universidades, centros universitários e faculdades.

O quadro 1 mostra a descrição das dez dimensões avaliativas apresentadas pelo documento oficial do SINAES - da concepção à regulamentação, bem como a quantidade de indicadores de qualidades atribuídos para cada uma das dimensões (BRASIL, 2009). 
Tabela 1: Dimensões avaliativas do SINAES e respectivas quantidades de indicadores

\begin{tabular}{|c|c|}
\hline Dimensão & $\begin{array}{l}\text { Quantidade de } \\
\text { Indicadores }\end{array}$ \\
\hline 1. A missão e o plano de desenvolvimento institucional & 2 \\
\hline $\begin{array}{l}\text { 2. A política para o ensino, a pesquisa, a pós-graduação, a extensão e as respectivas } \\
\text { normas de operacionalização, incluídos os procedimentos para estímulo à produção } \\
\text { acadêmica, para as bolsas de pesquisa, de monitoria e demais modalidades. } \\
\text { 3. A responsabilidade social da instituição, considerada especialmente no que se } \\
\text { refere à sua contribuição em relação à inclusão social, ao desenvolvimento econômico } \\
\text { e social, à defesa do meio ambiente, da memória cultural, da produção artística e do } \\
\text { patrimônio cultural. }\end{array}$ & 4 \\
\hline 4. A comunicação com a sociedade. & 3 \\
\hline $\begin{array}{l}\text { 5. As políticas de pessoal, de carreiras do corpo docente e corpo técnico } \\
\text { administrativo, seu aperfeiçoamento, seu desenvolvimento profissional e suas } \\
\text { condições de trabalho. } \\
\text { 6. Organização e gestão da instituição, especialmente o funcionamento e } \\
\text { representatividade dos colegiados, sua independência e autonomia na relação com a } \\
\text { mantenedora, e a participação dos segmentos da comunidade universitária nos } \\
\text { processos decisórios. }\end{array}$ & 6 \\
\hline $\begin{array}{l}\text { 7. Infraestrutura física, especialmente a de ensino e de pesquisa, biblioteca, recursos } \\
\text { de informação e comunicação. }\end{array}$ & 5 \\
\hline $\begin{array}{l}\text { 8. Planejamento e avaliação, especialmente em relação aos processos, resultados e } \\
\text { eficácia da autoavaliação institucional. }\end{array}$ & 3 \\
\hline 9. Políticas de atendimento aos estudantes & 4 \\
\hline $\begin{array}{l}\text { 10. Sustentabilidade financeira, tendo em vista o significado social da continuidade } \\
\text { dos compromissos na oferta da educação superior. }\end{array}$ & 3 \\
\hline
\end{tabular}

A análise crítica do instrumento de avaliação externa proposto pelo SINAES mostra a existência de lacunas em cinco das dez dimensões avaliativas, nas quais poderiam ser agregados indicadores que contemplem as especificidades dos Institutos Federais, valorizando a política que essas instituições de ensino propagam.

Na segunda dimensão avaliativa do documento, denominada "A política para o ensino, a pesquisa, a pós-graduação, a extensão e as respectivas normas de operacionalização, incluídos os procedimentos para estímulo à produção acadêmica, para as bolsas de pesquisa, de monitoria e demais modalidades", poderia ser acrescentado um indicador referente à marca teórica dos Institutos Federais, ou seja, à verticalização do ensino, considerando a coerência dessa prática na instituição com os documentos oficiais que lhe fundamentam.

Ainda na segunda dimensão, no que diz respeito às políticas voltadas à pesquisa, poderia ser acrescentado um indicador relacionando à aplicação da pesquisa em contexto local, ou seja, os Institutos Federais, devido às suas características, desenvolvem a pesquisa aplicada ao locus onde se inserem e às necessidades locais e regionais, não se restringindo à pesquisa meramente acadêmica (básica) observada nas demais instituições de educação superior. 
A terceira dimensão avaliativa proposta pelo SINAES trata da "responsabilidade social da instituição, considerada especialmente no que se refere à sua contribuição em relação à inclusão social, ao desenvolvimento econômico e social, à defesa do meio ambiente, da memória cultural, da produção artística e do patrimônio cultural", novamente no sentido da proposição dos Institutos Federais com as necessidades locais e regionais, se faz necessário o acréscimo de um indicador que transponha o compromisso dessas instituições em sua relação com a sociedade local e regional com a premissa de contribuição para a esfera global.

A quarta dimensão avaliativa - "A comunicação com a sociedade", é a dimensão em que se faz possível acrescentar um dos pontos mais importantes atribuídos ao compromisso dos Institutos Federais, que é a sua relação com a sociedade mediada pelo mundo do trabalho, ou seja, o compromisso de uma educação não mais voltada apenas para as necessidades do mercado de trabalho, mas para a formação de cidadãos trabalhadores que exerçam o trabalho em seu princípio educativo, utilizando de suas potencialidades na solução de problemáticas, e fazendo-a de forma crítica e reflexiva.

Tabela 2: Proposta de acréscimo de indicadores específicos em cinco dimensões avaliativas do SINAES

\begin{tabular}{|c|c|}
\hline Dimensão & Indicadores Específicos aos IFs \\
\hline \multirow{2}{*}{$\begin{array}{l}2 \text { - A política para o ensino, a pesquisa e a extensão } \\
\text { e as respectivas normas de operacionalização, } \\
\text { incluídos os procedimentos para estímulo à } \\
\text { produção acadêmica, para as bolsas de pesquisa, de } \\
\text { monitoria e demais modalidades. }\end{array}$} & $\begin{array}{l}\text { Coerência da política para as práticas de } \\
\text { verticalização do ensino com os documentos } \\
\text { oficiais. }\end{array}$ \\
\hline & $\begin{array}{l}\text { Políticas institucionais de pesquisa aplicada } \\
\text { à necessidade do contexto social local. }\end{array}$ \\
\hline $\begin{array}{l}3 \text { - A responsabilidade social da instituição, } \\
\text { considerada especialmente no que se refere à sua } \\
\text { contribuição em relação à inclusão social, ao } \\
\text { desenvolvimento econômico e social, à defesa do } \\
\text { meio ambiente, da memória cultural, da produção } \\
\text { artística e do patrimônio cultural. }\end{array}$ & $\begin{array}{l}\text { Relação da IES com a sociedade: } \\
\text { Compromisso com os arranjos sociais e } \\
\text { desenvolvimento local da região. }\end{array}$ \\
\hline 4 - A comunicação com a sociedade. & $\begin{array}{l}\text { Relação da IES com o mundo do trabalho } \\
\text { partindo do desenvolvimento da esfera } \\
\text { local. }\end{array}$ \\
\hline $\begin{array}{l}7 \text { - Infraestrutura física, especialmente a de ensino e } \\
\text { de pesquisa, biblioteca, recursos de informação e } \\
\text { comunicação. }\end{array}$ & $\begin{array}{l}\text { Coerência da infraestrutura física com o } \\
\text { modelo verticalizado de ensino: } \\
\text { Compartilhamento de espaços de ensino e } \\
\text { aprendizagem. }\end{array}$ \\
\hline $\begin{array}{l}\text { 8- Planejamento e avaliação, especialmente em } \\
\text { relação aos processos, resultados e eficácia da } \\
\text { autoavaliação institucional. }\end{array}$ & $\begin{array}{l}\text { A autoavaliação institucional deve } \\
\text { compreender a instituição como um todo e } \\
\text { não apenas pela oferta de educação } \\
\text { superior. }\end{array}$ \\
\hline
\end{tabular}

Outro ponto analisado, talvez um dos mais importantes até o momento, trata da sétima dimensão avaliativa - "Infraestrutura física, especialmente a de ensino e de pesquisa, biblioteca, recursos de informação e comunicação", neste caso os Institutos Federais acabam desfavorecidos no momento da avaliação, pois não possuem ambientes específicos aos cursos superiores da mesma forma que as universidades estão organizadas. Isso ocorre devido à marca teórica que 
permeia as ações dessas instituições, que é a verticalização do ensino. Devido ao modelo curricular verticalizado, os estudantes dos diferentes níveis e modalidades de ensino compartilham os espaços de aprendizagem, como os laboratórios, por exemplo, e conforme os documentos oficiais (BRASIL, 2008), esse compartilhamento aproxima as diferentes formações. Neste caso se faz necessário que essa característica singular seja contemplada nessa dimensão.

Por fim, na oitava dimensão avaliativa - "Planejamento e avaliação, especialmente em relação aos processos, resultados e eficácia da autoavaliação institucional", acredita-se na importância de um indicador que considere a avaliação institucional pelo todo, ou seja, não apenas pela oferta da educação superior, pois os Institutos Federais não ofertam apenas esse nível de ensino. A autoavaliação institucional deve considerar a instituição na sua complexidade organizacional, diferenciada das universidades, centros universitários e faculdades.

Partindo dessas reflexões que embasam a construção de novos indicadores, o quadro 2, traz as respectivas dimensões nas quais poderiam ser acrescentados indicadores específicos aos Institutos Federais, aliados aos indicadores já propostos.

\section{CONSIDERAÇÕES FINAIS}

O presente artigo representou parte dos achados de uma investigação voltada para o estudo identitário dos Institutos Federais de Educação, Ciência e Tecnologia. Nesse sentido problematizou a necessidade de que exista uma prática coerente entre as políticas de Estado e de governo no que se refere à regulação e avaliação institucional voltadas para os Institutos Federais. Se essas instituições foram criadas e implementadas com características tão próprias é porque seu lugar no cenário educacional, imagina-se, foi pensado de forma estratégica para que ocupasse um papel ainda não preenchido pelas instituições já existentes. Há, pois, que se ter unidade nas políticas e ações para que a identidade institucional não seja distorcida pela própria política que a constituiu.

\section{REFERÊNCIAS}

1. BERNSTEIN, B. Pedagogía, Control Simbólico e Identidad. Madrid: Morata, 1998.

2. BRASIL. Ministério da Educação. Concepção e Diretrizes, Instituto Federal de Educação, Ciência e Tecnologia. PDE. Brasília, 2008.

3. BRASIL. Ministério da Educação/Inep-Instituto Nacional de Estudos e Pesquisas Educacionais Anísio Teixeira. SINAES - Sistema Nacional de Avaliação da Educação Superior: da concepção à regulamentação. 5. ed. Brasília: Inep, 2009.

4. FRIGOTTO, G., CIAVATTA, M.; RAMOS, M. O trabalho como princípio educativo no projeto de educação integral de trabalhadores. In: COSTA, H.; CONCEIÇÃO, M. (Org.). Educação integral e sistema de reconhecimento e certificação educacional e profissional. São Paulo: CUT, 2005.

5. LEITE, D. Reformas Universitárias. Avaliação institucional participativa. Petrópolis: Vozes, 2005.

6. PACHECO, Eliezer. Institutos Federais uma revolução na educação profissional e tecnológica. São Paulo: Moderna, 2011. 